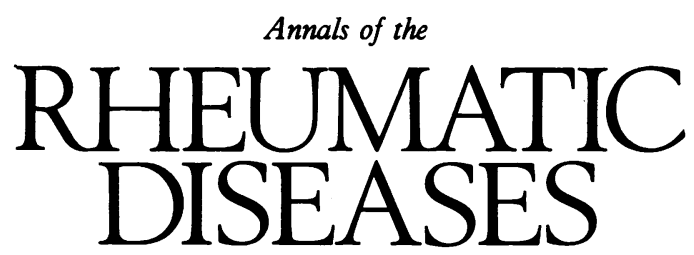

Leaders

\title{
Treatment of osteoporosis: current and future
}

Political parties are always seeking the 'big idea' which will encapsulate their philosophy and catch the imagination of the electorate. This is a general phenomenon, and as evidence accumulates that preventive therapy is effective the 'big idea' in osteoporosis shifts to the treatment of established disease. The strategies which will be needed, however, differ fundamentally from those which have been so successful in prevention.

Bone architecture and the response to treatment Osteoporosis is a disorder of remodelling, ${ }^{1}$ which involves not only a loss of bone but in many cases a destruction of the trabecular elements themselves. ${ }^{12}$ In particular, selective destruction of horizontal bracing trabeculae leads to a reduction in the mechanical strength of bone out of proportion to the amount of bone removed.

The aim of preventive treatment is to maintain bone mass on the reasonable assumption that this will preserve bone architecture and its mechanical integrity. The problem with established disease is that although treatment may shift the remodelling process towards net bone accretion and increased trabecular width, the mechanical strength of bone may not be significantly increased unless trabecular continuity is restored. ${ }^{3}$ These considerations also have important implications for the way in which the response to treatment is monitored. Although measurement of bone mineral density is a reasonable way of assessing the effectiveness of preventive treatment, ${ }^{4}$ it will not reflect the consequences of, nor changes in, the altered bone architecture of established osteoporosis. Treatment of the established disease needs to be judged by its effect on fracture rate.

These differences are well illustrated by the recent studies of the use of sodium fluoride 5 and disodium etidronate $^{67}$ in the treatment of established osteoporosis. Although sodium fluoride produced impressive changes in bone mineral density, the incidence of vertebral crush fractures was not improved. In contrast, disodium etidronate had only a very modest effect on bone mineral density but did seem to reduce the rate of vertebral deformation.

\section{Preventive treatment}

Oestrogen replacement therapy shows a dose dependent effect $^{89}$ on the reduction of postmenopausal bone loss ${ }^{10-12}$ and fracture risk. ${ }^{13-15}$ To be effective in preventing fractures it probably needs to be taken for five to 10 years, ${ }^{3}$ and this presents problems with uptake of, and compliance with, treatment. Although there is considerable interest in hormone replacement therapy among women, ${ }^{16}$ the actual uptake may only be $20 \%$ with bias towards social classes I and II. ${ }^{17}$ Older women are less likely to accept treatment, ${ }^{18}$ even though there is evidence that bone loss can be prevented, at least up to the age of 70 years. ${ }^{19} 20$ There is a surprising paucity of data relating to the long term compliance with hormone replacement therapy, but compliance may be as low as $30 \% .^{21}$ Regular menstrual bleeding is a major disincentive, ${ }^{22}$ though this is clearly not a problem for the $17-35 \%$ of the British or American target population who have already had a hysterectomy. ${ }^{23} 24$ Combination of continuous progestogen with oestrogen may offer freedom from regular bleeding. ${ }^{19} 25$ and may help compliance provided that it is shown that the progestogen regimen has no adverse effects either on bone or cardiovascular risk.

\section{Treatment of established osteoporosis}

Bone mass may be increased either by inhibition of bone resorption or by stimulation of formation. This may not prevent fractures in established osteoporosis, however, unless treatment also influences the architectural distortion which is inherent in the osteoporotic process. Bisphosphonates or other osteoclast inhibitors can be used to inhibit and uncouple the initial short phase of osteoclastic resorption from the longer phase of bone formation. ${ }^{26} 27$ This results in a transient gain of bone whose magnitude decreases with time as bone formation declines to match the reduced rate of resorption. Two recent double blind placebo controlled studies using cyclical disodium etidronate suggested that although the increment of bone mineral density was a modest $2-3 \%$ a year, there was also a reduction in the incidence of new vertebral fractures. ${ }^{6}$ This latter effect may be due to a reduction in the activation frequency of new bone remodelling units, which in turn reduces the chance with which already thin trabecular plates may be perforated with a consequent loss of mechanical strength.

Neither study was without problems: both used a semiquantitative assessment of change in vertebral configuration without direct measurement. In the three year study ${ }^{6} 26 / 66$ (39\%) patients left because of non-compliance, although in the other $369(86 \%)$ of the 429 women completed two years. The small study size was reflected in a failure to show an overall benefit for etidronate after three years, though fracture rates were significantly reduced if the last 90 weeks of treatment were analysed separately. In the larger study 
etidronate reduced the incidence of new spinal fractures, and this was most obvious in those with the lowest pretreatment spinal bone mineral density. Non-vertebral fractures $(n=67)$ were evenly spread through the placebo and treatment groups, though it was ironic that six out of nine osteoporotic fractures (hip, pelvis, wrist) occurred in the etidronate treated group.

Although both studies used a cyclical etidronate regimen, the prolonged half life of bisphosphonates in bone makes it doubtful that these effects were due to a transient rather than a sustained depression of osteoclastic resorption. Indeed, continuous administration of pamidronate (APD) apparently results in a sustained increase in bone mass over several years. ${ }^{27}$ It does seem that despite continued bisphosphonate treatment bone turnover does not become completely suppressed but reaches a plateau value after several months' treatment. ${ }^{27} 28$ The treatment free period with etidronate may be important as one study using a free period of just eight weeks actually showed a decrease in bone density over two years, whereas the control group showed no change. ${ }^{29}$ This may be related to the greater inhibition of osteoblastic activity seen with etidronate compared with newer bisphosphonates. ${ }^{30-32}$ This serves to emphasise that individual bisphosphonates may have different profiles of activity which may be important in treatment. $^{32}$

A potential pitfall in bisphosphonate treatment is that by reducing bone turnover, a progressively greater proportion of the skeleton will be composed of old bone making it more liable to fatigue fractures that might not be repaired quickly enough to avoid complete fractures. ${ }^{33}$ Thus after several years' treatment the benefits of any maintenance or increase in bone mass might be lost owing to the increased possibility of fracture. These studies with bisphosphonates are important because they show that reductions in fracture incidence may not only depend on changes in bone mass but also may include an element of architectural change. Clearly, longer term data are needed before their use becomes widespread.

Sodium fluoride is the other major contender for treatment of established osteoporosis and provides interesting comparisons with the bisphosphonates. Fluoride is mitogenic for osteoblasts, and several studies have shown that bone mineral density increases by $8-10 \%$ a year. ${ }^{54-37}$ Doses of $50-75 \mathrm{mg} /$ day produce serum fluoride concentrations of $5-10 \mu \mathrm{mol} / 1 .^{536}$ Several studies have shown a significant prevalence of side effects, which include nausea, vomiting or epigastric pain, and the leg pain syndrome. These effects can be minimised or avoided by using lower doses or slow release preparations. ${ }^{35} 36$ The critical issue is whether fracture rate is influenced by treatment. Two recent large four year prospective, double blind, placebo controlled trials of sodium fluoride failed to show a statistically significant reduction in vertebral crush fractures. ${ }^{5} 37$ Of much greater concern was the increase in non-vertebral fractures, ${ }^{5} 3438$ and this raises the issue of whether the anabolic effect of fluoride on trabecular bone is essentially linked to loss of cortical bone. ${ }^{5439}$ Measurement of bone mineral density at the hip may not resolve these problems because loss of cortical bone may be obscured by an increase in the trabecular component. The fracture propensity may be further increased by a qualitative defect in fluoride treated bone which includes increased crystallinity, decreased elasticity, and tensile strength. ${ }^{40}$ Although slow release formulations may reduce the incidence of side effects, ${ }^{36}$ the lack of a relation between serum fluoride concentration and fracture rate suggests that dose manipulation will not solve the problems of axial and cortical bone balance.

The opposing effects of fluoride on bone quality and quantity and fracture incidence may also influence the optimum duration of treatment. In the Mayo Clinic study treatment did not increase the time to the first new vertebral fracture, though the relative risk of this event showed the maximum reduction at the end of the second and third years of treatment. Previous studies showing beneficial effects on fracture rate ${ }^{34-36}$ have been of two to three years' duration, and this aspect of fluoride treatment warrants further examination. Severity of osteoporosis does not seem to be a factor in the conflicting effects on fracture rate. It might be supposed that some patients have experienced such severe bone loss that the increments produced by fluoride were insufficient to exceed the fracture threshold, particularly as this might be raised as a consequence of the qualitative defect of fluoride treated bone. Treatment and placebo groups, however, have generally been well matched for clinical severity ${ }^{35}$ and bone mineral density, ${ }^{5}$ and in one study those with the most severe osteoporosis showed the most impressive increments in bone mineral density. ${ }^{39}$ Thus the current role of sodium fluoride remains uncertain, but its use should be avoided in patients with significant cortical osteoporosis.

\section{Future treatments}

There has been considerable recent interest in the way that the major calcium regulating hormones affeçt bone remodelling by modulating local growth fracture production or function. ${ }^{41} 42$ Experience from pathological bone remodelling in Paget's disease or carcinoma of the prostate shows that under appropriate circumstances there may be proliferation of trabecular elements and modification of bone architecture. There is also experimental evidence in dogs that aluminium salts lead to neo-osteogenesis with an increase in trabecular plate number and spinal bone density. ${ }^{43}$ There are, however, a number of obstacles to the use of local bone growth factors in the treatment of established osteoporosis. Because their actions are not specific to bone their delivery to the remodelling surface must be targeted to avoid systemic side effects. Alternatively, their local release can be stimulated by the systemic administration of hormones or drugs. Finally, the complexity of the interrelations between the rapidly expanding number of local regulators of bone remodelling makes it more difficult to identify optimal therapeutic regimens.

City Hospital,

Hucknall Road

Nottingham NGS IPB

M D STONE D J HOSKING

Correspondence to: Dr Hosking.

1 Parfitt A M. Quantum concept of bone remodeling and turnover: implications for the pathogenesis of osteoporosis. Calcif Tissue Int 1979; 28: 1-5.

Dempster D W, Shane E, Horburt W S, Lindsay R. A simple method for correlative light and scanning electron microscopy of human iliac crest bone biopsies: quantitative observations in normal and osteoporotic subjects. f Bone Miner Res 1986; 1: 15-21

3 Christiansen C, Lindsay R. Estrogens, bone loss and preservation. Osteoporosis Intemational 1990; 1: 7-13.

4 Anonymous. Bone densitometry and clinical decision making in osteoporosis [editorial]. Amon Intern Med 1988; 108: 293-5.

5 Riggs B L, Hodgson S F, O'Fallon W N, et al. Effect of fluoride treatment on the fracture rate in post menopausal women with osteoporosis. $N$ Engl $\mathcal{F}$ Med 1990; 322: 802-9.

6 Storm T, Thamsborg G, Steiniche T, Genant H K, Sørensen O H. Effects of intermittent cyclical etidronate therapy on bone mass and fracture rate in women with post menopausal osteoporosis. N Engl f Med 1990; 322: 1265-71.

Watts N B, Harris S T, Genant H K, et al. Intermittent cyclical etidronate treatment of post menopausal osteoporosis. $N$ Engl 7 Med 1990; 323: 73-9.

Christensen $M S$, Hagen C Christiansen C Transbol I Dose-response even evaluation of cyclic estrogen/gestagen in post menopausal women: placebo controlled trial of its gy

9 Lindsay R, Hart D M, Clarke D M. The minimum effective dose of estrogen for prevention of post menopausal bone loss. Obstet Gynecol 1983; 63: $759-63$.

10 Lindsay R, Hart D M, Forrest G, Baird C. Prevention of spinal osteoporosis in oophorectomized women. Lancet 1980; ii: 1151-4. 
11 Christiansen C, Christiensen M S, McNair P, Hagen C, Stocklund K-E, Transbol I. Prevention of early post menopausal bone loss: controlled 2 year study in 315 normal females. Eur $\mathcal{f}$ Clin Invest 1980; 10: 273-9.

12 Lindsay R, Hart D M, Purdie D, Ferguson M M, Clark A S, Kraszewski A. Comparative effects of oestrogen and a progestogen on bone loss in post menopausal women. Clin Sci 1978; 54: 193-5.

13 Weiss N S, Ure C L, Ballard J H, Williams A R, Daling J R. Decreased risk of fractures of the hip and lower forearm with post menopausal use of estrogen. N Engl f Med 1980; 303: 1195-8.

14 Ettinger B, Genant H K, Cann C E. Long term estrogen replacement therapy prevents bone loss and fractures. Ann Intern Med 1985; 102: 319-24.

15 Paganini-Hill A, Ross R K, Gerkins V R, Henderson B E, Arthur M, Mack T M. Menopausal estrogen therapy and hip fractures. Ann Intern Med 1981; 95: 28-31.

16 Draper J, Roland M. Perimenopausal womens views on taking hormone replacement therapy to prevent osteoporosis. $B M \mathcal{F} 1990$; 300: 786-8.

17 Coope J. Perimenopausal womens views on hormone replacement therapy. BMF 1990; 300: 1526.

18 Wallace W A, Price V H, Elliott C A, MacPherson M B A, Scott B W. Hormone replacement therapy acceptability to Nottingham post menopausa women with a risk factor for osteoporosis. F $R$ Soc Med 1990; 83: 699-701.

19 Christiansen C, Riis B J. 17ß Estradiol and continuous norethisterone: a unique treatment for established osteoporosis in elderly women. $\mathcal{f} \mathrm{Clin}$ Enique treatment for established ostab $1990 ; 71: 836-41$.

20 Lindsay $R$, Tohme J. Estrogen treatment of patients with established post menopausal osteoporosis. Obstet Gynecol 1990; 76: 1-6.

21 Ravnikar V A. Compliance with hormone therapy. Am F Obstet Gymecol 1987 156: $1332-4$.

22 Hahn R G. Compliance considerations with estrogen replacement: withdrawal bleeding and other factors. Am $\mathcal{F}$ Obstet Gynecol 1989; 161: 1854-8.

23 Coulter A, McPherson K, Vessey M. Do British women undergo too many or too few hysterectomies? Soc Sci Med 1988; 27: 987-94.

24 Howe H L. Age specific hysterectomy and oophorectomy prevalence rates and the risks for cancer of the reproductive system. Am f Public Health 1984 74: $560-3$.

25 Magos A L, Brincat $M$, Studd J W, Wardle P, Schlesinger P, O'Dowd T. Amenorrhoea and endometrial atrophy with continuous oral estrogen and progestogen therapy in post menopausal women. Obstet Gymecol 1985; 65:

26 Frijlink W B, TeVelda J, Bijvoet O L M, Heynen G. Treatment of Paget's disease with (3-amino-1-hydroxypropylidene)-1,1-bisphosphonate (APD) Lancet 1979; i: 799-803.

27 Valkema R, Vismans F-J F E, Papapoulos S E, Pauwels E K J, Bijvot O L $M$. Maintained improvement in calcium balance and bone mineral conten in patients with osteoporosis treated with the bisphcsphonate, APD. Bone Miner 1989; 5: 183-92.

28 Reid I R, Schooler B A, Stewart A W. Prevention of glucocorticoid-induced osteoporosis. F Bone Miner Res 1990; 5: 619-23.

29 Pacifici A, McMurtry C, Vered I, Rupich R, Avioli L V. Coherence therapy does not prevent axial bone loss in osteoporotic women: a preliminary comparative study. 7 Clin Endocrinol Metab 1988; 66: 747-53.

30 McLoskey E V, Yates A J P, Beneton M N C, Galloway J, Harris S, Kanis A. Comparative effects of intravenous diphosphonates on calcium and skeletal metabolism in man. Bone 1987; 8 (suppl 1): S35-41.

31 Boyce B F, Smith L, Fogelman I, Johnstone E, Ralston S, Boyle I T. Foca osteomalacia due to low-dose diphosphonate therapy in Paget's disease. Lancet 1984; i: $821-4$.

32 Fleisch $H$. Bisphosphonates: mechanism of action and clinical applications. In: Peck $\mathbb{W} \mathrm{A}$, ed. Bone and mineral research. Annual 1 . Amsterdam: Excepta Medica, 1983: 319-57.

33 Parfitt A M. Bone remodelling and bone loss: understanding the pathophysiology of osteoporosis. Clin Obstet Gynecol 1987; 30: 789-811.

34 Gutteridge D H, Price R I, Nicholson G C, et al. Fluoride in osteoporotic vertebral fractures - trabecular increase, vertebral protection; femoral fractures. Copenhagen International Symposium on Osteoporosis. Denmark: Glostrup Hospital, 1984: 705-7.

35 Mamelle N, Meunier P J, Dusan R, et al. Risk-benefit ratio of sodium fluoride treatment in primary vertebral osteoporosis. Lancet 1988; ii: $361-5$.

36 Pak C Y C, Sakhaee K, Zerwekh J E, et al. Safe and effective treatment of osteoporosis with intermittent slow release sodium fluoride: augmentation of vertebral bone mass and inhibition of fractures. $\mathcal{F}$ Clin Endocrinol Metab 1989; 68: 150-9.

37 Kleerekoper M, Peterson E, Philips E, et al. Continuous sodium fluoride therapy does not reduce vertebral fracture in post menopausal osteoporosis. f Bone Miner Res 1989; 4 (suppl 1): S376.

38 Gerster J C, Charhon S A, Jaeger P J, et al. Bilateral fractures of femoral neck in patients with moderate renal failure receiving fluoride for spinal osteoporosis. BMF 1983; 287: 723-5.

39 Hodsman A B, Drost D J. The response of vertebral bone mineral density during the treatment of osteoporosis with sodium fluoride. $\mathcal{f}$ Clin Endocrinol Metab 1989; 69: 932-8.

40 Eanes $E$ D, Reddi A H. The effect of fluoride on bone mineral apatite. Metab Bone Dis Relat Res 1979; 2: 3-10.

41 Raisz L G. Local and systemic factors in the pathogenesis of osteoporosis. $N$ Engl f Med 1988; 318: 818-28.

42 Canalis E, McCarthy T, Centrella $M$. Growth factors and the regulation of bone remodeling. $\mathcal{F}$ Clin Invest 1988; 81: 277-81.

43 Quarles L D, Murphy G, Vogler J B, Drezner M K. Aluminium induced neoosteogenesis: a generalized process affecting trabecular networking in the axial skeleton. F Bone Miner Res 1990; 5: 625-35. 